DOI: 10.17707/AgricultForest.64.2.05

\author{
Nayer MOHAMMADKHANI ${ }^{1}$
}

\title{
EFFECTS OF SALINITY ON PHENOLIC COMPOUNDS IN TOLERANT AND SENSITIVE GRAPES
}

\section{SUMMARY}

Salinity is a major environmental stress and grape is classified as a moderately sensitive plant to salinity. Plants have anti-oxidative systems involving antioxidant enzymes and secondary metabolites like phenolic compounds. The aim of this study was to examine the salinity induced alterations, PAL enzyme activity and total phenolics contents in four grape genotypes. In this study two tolerant (Gharashani and H6) and two sensitive (Shirazi and GhezelUzum) grapes - according to screening experiments under salinity- were selected. $50 \mathrm{mM} \mathrm{NaCl}$ was used for salinity treatment.

Total phenolics content and phenylalanine ammonia-lyase (PAL) activity increased in all the genotypes under salinity. A positive significant correlation $(P<0.01, r>0.8)$ was observed between total phenolics and PAL activity in leaves and roots of grapes. Ten phenolic acids including hydroxybenzoic acid and hydroxycinnamic acid derivatives were analyzed. Our tolerant and sensitive genotypes showed main differences in phenolic compounds accumulation under salinity. Some compounds like gallic, syringic and p-coumaric acids accumulated higher in tolerant genotypes and others like vanillic, caffeic and sinapic acids accumulated in sensitive genotypes. Considering our results it seems that syringic and p-coumaric acids -that was higher in leaves and roots of tolerant genotypeshad a key role in salinity tolerance.

Keywords: Abiotic stress, phenylalanine ammonia-lyase activity, caffeic acid, p-coumaric acid

\section{INTRODUCTION}

Abiotic stresses like salinity decreases the plants growth and causes the osmotic stress (Xiong et al., 2002). Salinity induced some of the biochemical and physiological processes in plants. High level of salt produce reactive $\mathrm{O}_{2}$ species (ROS). To reduce damage, plants have evolved complex anti-oxidative systems, involving antioxidant enzymes and secondary metabolites like phenolic compounds (Posmyk et al., 2009). Antioxidant activity of phenolic compounds have been reported before (Wang and Nii, 2000). Flavonoids and other phenolics are scavengers of free radicals (Rice-Evans et al., 1997).

\footnotetext{
${ }^{1}$ Nayer Mohammadkhani, (corresponding author: n.mohammadkhani@urmia.ac.ir), Shahid Bakeri High Education Center of Miandoab, Urmia University, Urmia, IRAN.

Notes: The authors declare that they have no conflicts of interest. Authorship Form signed online.
} 
Grape (Vitis vinifera) is the plant that cultivated extensively in the world and is economically important. Salt stress have decreased grape yield. Vitis vinifera family is moderately sensitive to salt (Maas and Hoffman, 1977). Grapes contain valuable phenolic compounds (Fuleki and Ricardo-Da-Silva, 2003). Phenolics are considered for their important role in grape development and their beneficial health effects (Bub et al., 2003).

Phenols are important secondary metabolites that show antioxidant properties and play a key role in grape quality (Solecka and Kacperska, 2003) and defense under abiotic stresses (Amarowicz and Weidner, 2009). Polyphenols accumulated in Mentha pulegium plant under salt stress (Oueslati et al., 2010).

Phenolics mainly synthesize from cinnamic acid, which is produced by phenylalanine ammonia-lyase (PAL; EC 4.3.1.5) activity, the key enzyme between shikimate pathway and phenylpropanoid metabolism. Abiotic stresses increased PAL enzyme activity, which cause the accumulation of phenolic acids (Solecka and Kacperska, 2003). So phenylalanine ammonia-lyase enzyme may induce stress tolerance via regulating the synthesis of phenolic compounds.

Some phenols like phenolic acids exists in most plants (Jwa et al., 2006). Phenolic acids including hydroxycinnamic acid and hydroxybenzoic acid derivatives are chemical compounds with one or more hydroxyl groups (Hounsome et al., 2008). Phenolics are good ROS scavengers that helping to plants in salt tolerance. The radical scavenging antioxidants inhibit oxidation of lipids, proteins and DNA. Phenolics act as antioxidants by inhibiting ROS production (Castellano et al., 2012).

The composition and quantity of phenolics is different in various species, varieties and the regions that grapes grown (Bautista-Ortin et al., 2007). Various treatments affect the final composition of phenolics content in natural fruits.

In this study four grape genotypes were compared from the view point of phenolic compounds under salinity. In previous experiments 18 grape genotypes was screened based on salinity tolerance (Mohammadkhani et al. 2013, 2014). The genotypes with higher (Gharashani and H6) and lower (Shirazi and GhezelUzum) salinity tolerance selected for determining phenolic compounds. In order to investigate salinity induced alterations in four grape genotypes, PAL enzyme activity and total phenolics contents were studied under salt stress.

\section{Plant growth conditions}

\section{MATERIAL AND METHODS}

Hardwood cuttings of grape genotypes [Gharashani, $\mathrm{H}_{6}(V$. vinifera $\mathrm{cv}$. GharaUzum $\times V$. riparia cv. Kober 5BB), Shirazi, and GhezelUzum] were obtained from Kahriz vineyard (agricultural research center, grape genotypes collection). The cuttings were soaked in IBA (indol-3-butyric acid) $0.1 \%$ (w/v) for 5-10 s and put in a mist house (relative humidity of $80 \%$ ) with a heat-bed temperature of $20-30{ }^{\circ} \mathrm{C}$. The rooted cuttings were transferred to aerated pots containing modified Hoagland nutrient solution (Mohammadkhani et al., 2014). Solutions were replaced every 2 days, also nutrient concentrations and the $\mathrm{pH}$ of 
the solutions were monitored daily (maintained within a range of 6.0-6.5). Our experimental design was Complete Randomized Design (CRD).

\section{Salinity treatments}

Two months old plants were treated with $50 \mathrm{mM} \mathrm{NaCl}$ (threshold salinity that induced osmotic stress in the genotypes according to our screening). Plants were collected at different time points (0, 24 hours, 7 days and 14 days) after salinity and stored at $-80{ }^{\circ} \mathrm{C}$ until phenolic compounds extraction.

\section{Total phenolic content assay}

Total phenolics were determined using Folin-Ciocalteu's reagent by Bonilla et al. (2003) method. Total phenolic content was reported as gallic acid in mg.g ${ }^{-1}$ of fresh weight.

\section{Determination of PAL activity}

Phenylalanine ammonia-lyase enzyme activity was measured by Solecka and Kacperska (2003) method. One unit of PAL activity was the enzyme amount that produce $1 \mu \mathrm{mol}$ of cinnamic acid in $1 \mathrm{~h}$.

\section{Extraction and measurement of phenolic acids by HPLC}

Phenolic acids were extracted by Hakkinen et al. (1998) method. Leaves and roots were grounded and rinsed with extraction solution (methanol, $\mathrm{HCl}$ and ascorbic acid) and sonicated for $2 \mathrm{~min}$. After $16 \mathrm{~h}$ shake in $35{ }^{\circ} \mathrm{C}$ water bath in the dark, the extract was centrifuged at $12000 \mathrm{~g}$ for $20 \mathrm{~min}$ and the samples filtered through a $0.45 \mu \mathrm{m}$ filter. Quantitative and qualitative analysis was done by reverse phase HPLC (Guillen et al., 1996). The HPLC apparatus consisted of a KNAUER (Germany), UV-Vis detector, and reverse-phase $\mathrm{C}_{18}$ column at 25 ${ }^{\circ} \mathrm{C}$. The volume injected was $20 \mu \mathrm{l}$. A flow rate of $0.8 \mathrm{ml} / \mathrm{min}$ was used with two solvents: solvent $\mathrm{A}, 10 \%$ methanol-2\% acetic acid in water; solvent $\mathrm{B}, 90 \%$ methanol-2\% acetic acid in water. The following proportions of solvent $\mathrm{B}$ were used: 0-15 $\mathrm{min}, 0-15 \% \mathrm{~B}$; 15-25 $\mathrm{min}, 15-50 \% \mathrm{~B}$; 25-30 $\mathrm{min}, 50-0 \% \mathrm{~B}$. The chromatograms were obtained at $280 \mathrm{~nm}$. Phenolic acids were identified by authentic standards. Standard acids (ascorbic acid, rutin, ferulic acid, caffeic acid, p-coumaric acid, p-hydroxybenzoic acid, vanillic acid, syringic acid, sinapic acid and gallic acid) were purchased from Sigma-Aldrich. Stock solutions of the standard acids were prepared in a concentration of $0.1 \mathrm{~g} / 10 \mathrm{ml}$ in pure methanol (Vekiari et al., 2008). ChromGate software was used for data processing.

\section{Statistical analysis}

Statistical analyses were done using SPSS (Version 19.0). Tukey's multiple range tests $(P<0.05)$ and GLM (General Linear Model) were performed to determine the significant difference among salinity treatments and genotypes. Correlations between different factors were calculated for all genotypes.

\section{RESULTS}

Effects of salinity on total phenolics contents and PAL activity

Salinity accumulated the phenolics in roots and leaves of all genotypes (Figures $1 \mathrm{~A}$ and 1B). 
After 14 days salinity, significant increase $(P<0.05)$ in phenolics contents was observed in roots of all genotypes. Total phenolic contents increased under salinity; that increase in leaves and roots of $\mathrm{H6}$ genotype was higher than others (8.25 and 4.24 fold more than control, respectively).

GLM (General Linear Model) analysis showed that the difference in increase of total phenolics contents among genotypes was significant $(P<0.05)$ in leaves. In leaves and roots the difference among all treatments was significant.

Salinity induced PAL activity in all treatments and all genotypes (Figures 1C and 1D). Increase in PAL activity of leaves was higher compare to roots. A maximum activity was observed in roots of Gharashani and leaves of H6 genotypes ( $46 \%$ and $71 \%$ more than control, respectively).
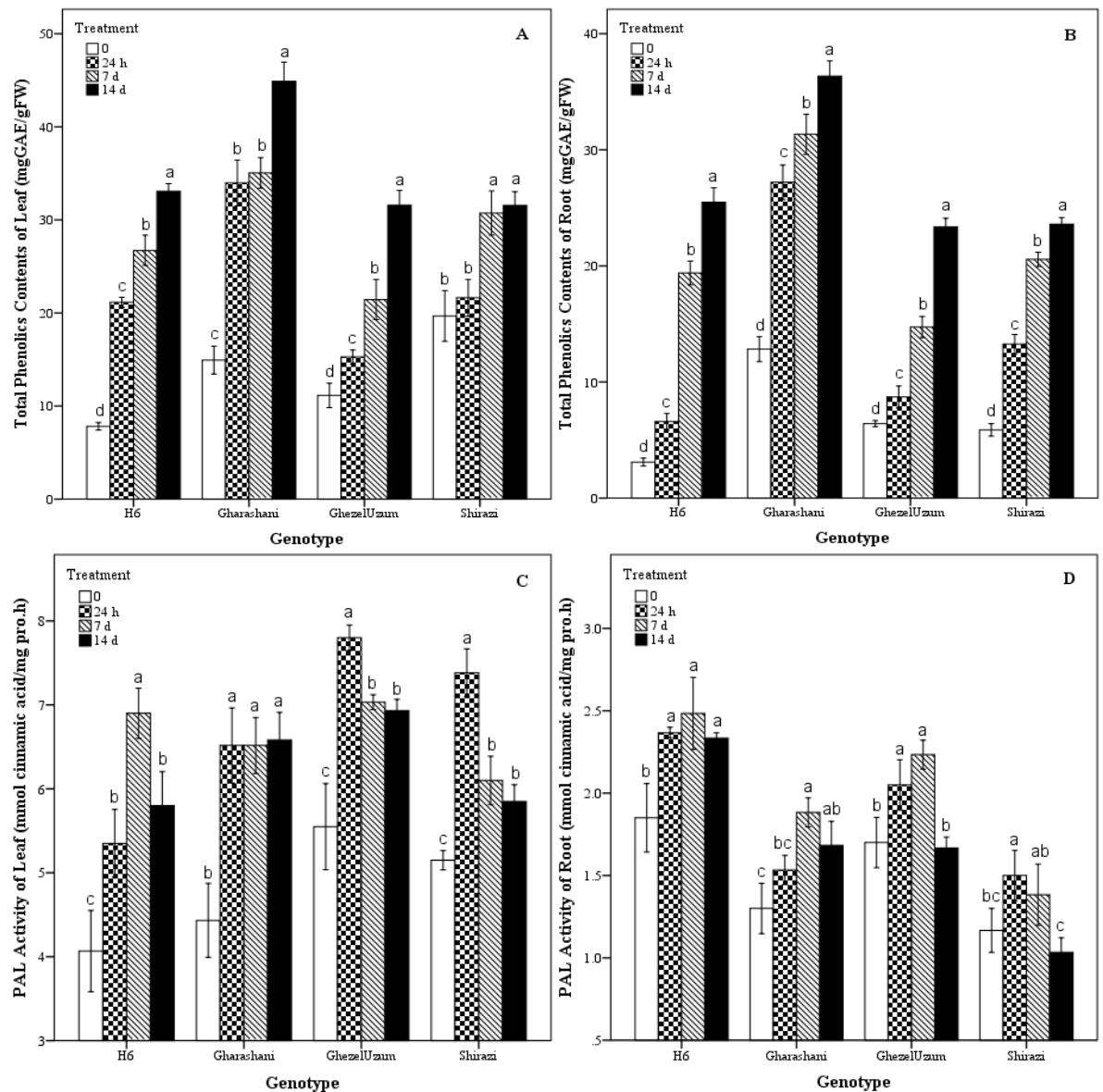

Figure 1. Total Phenolics contents in leaves (A) and roots (B) and PAL Activity in leaves (C) and roots (D) of four grape genotypes after 0, 24 hours, 7 days and 14 days treated by $50 \mathrm{mM} \mathrm{NaCl}$. Different letters above the columns indicate significant difference $(P<0.05)$ between the treatments according to Tukey's test. 
The difference in accumulation of PAL activity among genotypes was significant $(P<0.05)$ in roots. Also in roots the difference among treatments was significant $(P<0.05)$, but in leaves the difference between 24 hours and 7 days salinity was not significant.

\section{Effects of salinity on phenylpropanoids}

Ten phenolic acids, including 4 hydroxybenzoic acid derivatives (gallic acid, p-hydroxybenzoic acid, vanillic acid, and syringic acid), and 4 hydroxycinnamic acid derivatives (caffeic acid, p-coumaric acid, ferulic acid, and sinapic acid) as well as ascorbic acid and rutin were analyzed by HPLC. As shown in figures 2 to 5 and table 1, four hydroxybenzoic acid derivatives and five hydroxycinnamic acid derivatives accumulated significantly under salinity in our grape genotypes.
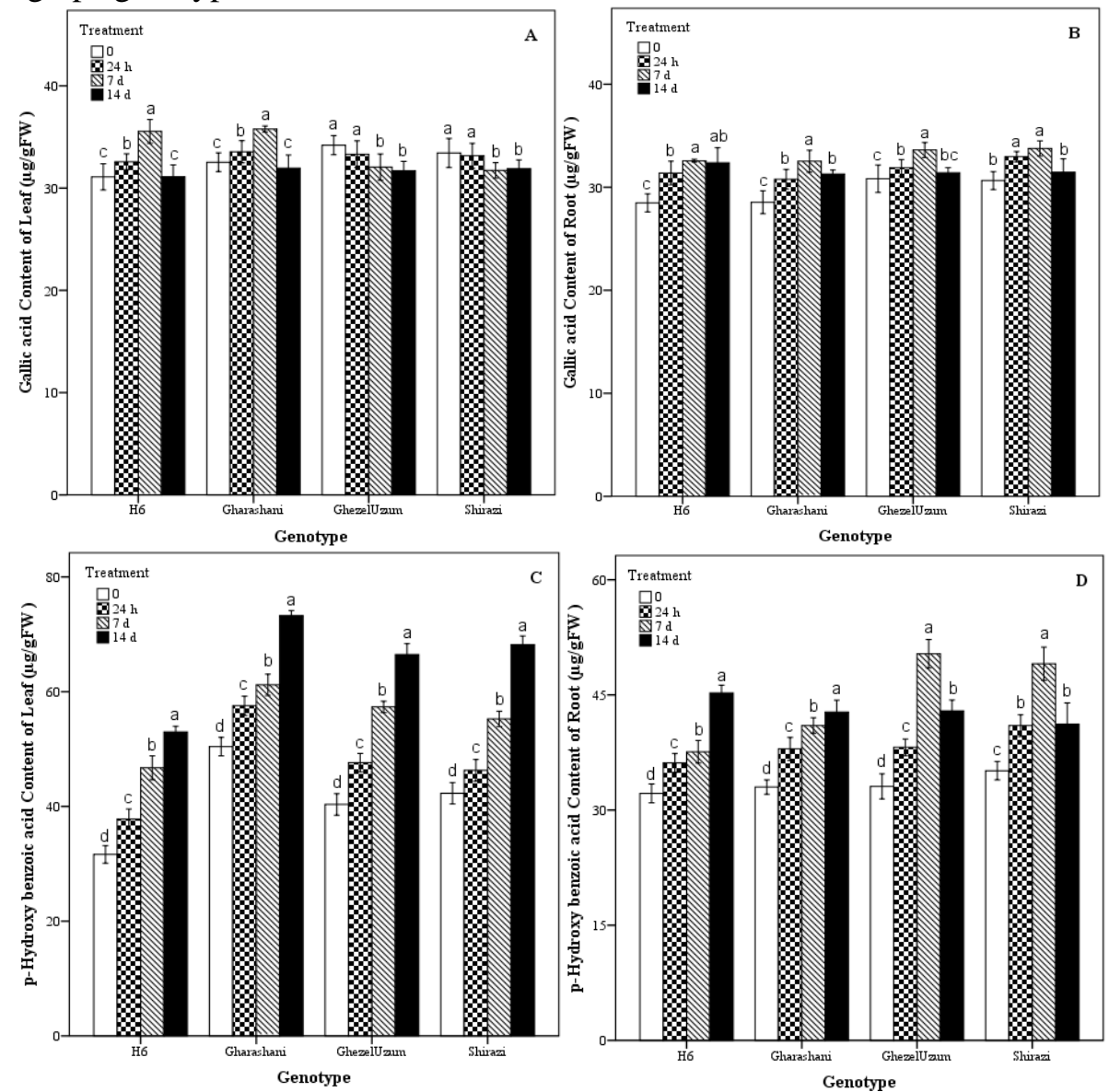

Figure 2. Gallic acid content in leaves (A) and roots (B) and p-Hydroxy benzoic acid content in leaves (C) and roots (D) of four grape genotypes after 0, 24 hours, 7 days and 14 days treated by $50 \mathrm{mM} \mathrm{NaCl}$. Different letters above the columns indicate significant difference $(P<0.05)$ between the treatments according to Tukey's test. 


\section{Effects of salinity on hydroxybenzoic acid derivatives}

Gallic acid

Gallic acid content increased in leaves of tolerant genotypes (Gharashani and H6), but after long time (14 days) there was no difference $(P<0.05)$ compare to control. Whereas in leaves of sensitive genotypes (GhezelUzum and Shirazi) it was decreased. In roots gallic acid accumulated under salinity, that accumulation in tolerant genotypes was higher compare to sensitive ones (Figures 2A and 2B).

The difference in gallic acid content of leaves between Gharashani and other genotypes was significant $(P<0.05)$, but H6, GhezelUzum and Shirazi genotypes showed no significant difference.

\section{P-hydroxy Benzoic Acid}

Leaves of our genotypes showed significant increase $(P<0.05)$ in phydroxy benzoic acid content, that increase in sensitive genotypes (GhezelUzum and Shirazi) was higher compare to tolerant ones (Gharashani and H6). We observed a significant increase in roots of tolerant genotypes. However all salinity treatments (time points) showed higher p-hydroxy benzoic acid content compare to control (Figures 2C and 2D).

The difference between sensitive genotypes in leaves and roots was not significant $(P<0.05)$, but tolerant genotypes showed significant difference. Also the difference between treatments was significant.

\section{Vanillic acid}

Under salinity vanillic acid content increased in leaves and roots compare to control, that increase in sensitive genotypes was higher compare to tolerant (Figures 3A and 3B). In leaves of tolerant genotypes we observed first increase and then decrease, but all time points showed higher content compare to control.

GLM (General Linear Model) analysis showed that the difference among genotypes and also among treatments in leaves and roots was significant $(P<0.05)$.

\section{Syringic acid}

Syringic acid increased in leaves and roots with time passing, that increase in tolerant genotypes was higher compare to sensitive ones (Figures 3C and 3D). In leaves the difference among genotypes was significant. The difference among all treatments in leaves and roots was significant $(P<0.05)$.

\section{Effects of salinity on hydroxycinnamic acid derivatives}

\section{Caffeic acid}

Caffeic acid content increased in leaves and roots with time passing, that increase in sensitive genotypes (GhezelUzum and Shirazi) was higher compare to tolerant ones (Figures 4A and 4B). Caffeic acid content increased in roots but we observed decrease under long time salinity.

The difference among genotypes in leaves was significant $(P<0.05)$, but roots of $\mathrm{H6}$ and GhezelUzum showed no significant difference. The difference among treatments in leaves and roots was significant. 

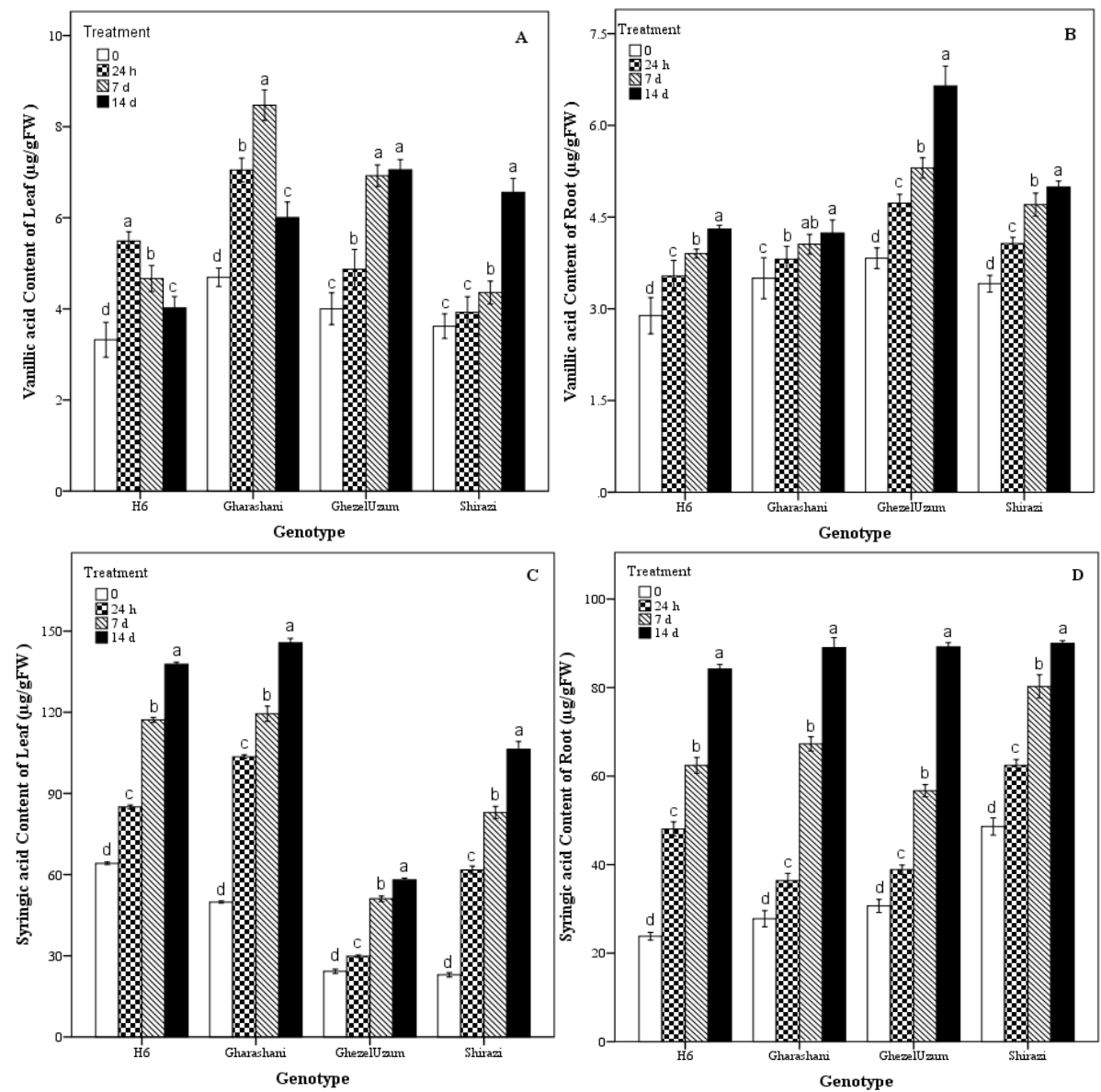

Figure 3. Vanillic acid content in leaves (A) and roots (B) and Syringic acid content in leaves (C) and roots (D) of four grape genotypes after 0, 24 hours, 7 days and 14 days treated by $50 \mathrm{mM} \mathrm{NaCl}$. Different letters above the columns indicate significant difference $(P<0.05)$ between the treatments according to Tukey's test.

\section{P-coumaric acid}

Higher content of p-coumaric was observed in leaves of tolerant genotypes after 7 days salinity and in sensitive ones after 24 hours (Figure 4C). In roots pcoumaric acid accumulated in tolerant genotypes (H6 and Gharashani) with time passing (Figure 4D). However p-coumaric acid content increased compare to control.

The difference among genotypes and also among treatments (time points) in leaves and roots was significant $(P<0.05)$.

\section{Ferulic acid}

Ferulic acid content increased under salinity, that increase in leaves of sensitive genotypes and roots of tolerant genotypes was higher than others 
(Figures 5A and 5B). Leaves of GhezelUzum and roots of $\mathrm{H6}$ showed higher ferulic acid accumulation compare to control.

The difference among all genotypes in leaves was significant $(P<0.05)$, but in roots Gharashani and GhezelUzum showed no significant difference. Also the difference among all treatments was significant.
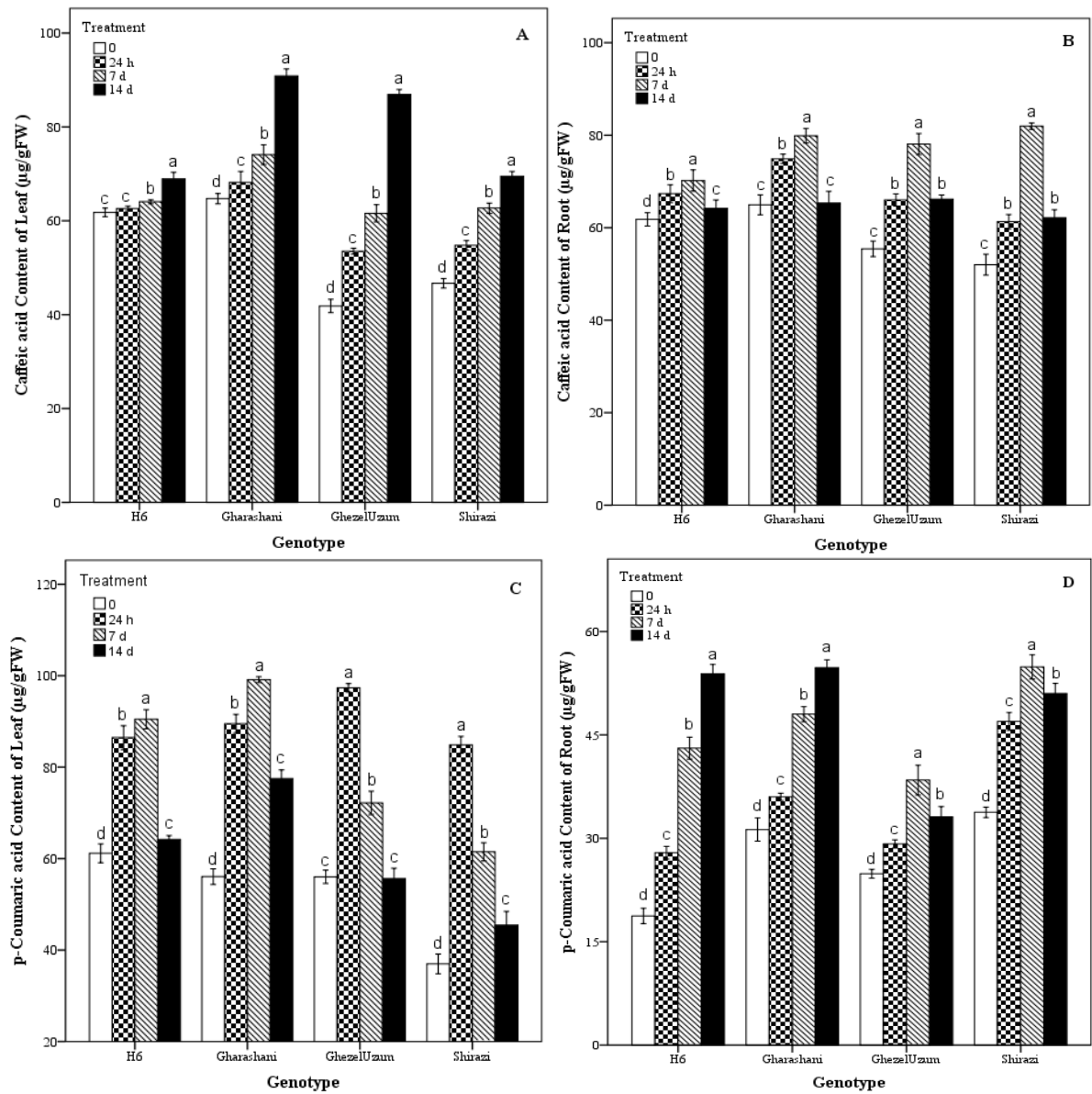

Figure 4. Caffeic acid content in leaves (A) and roots (B) and p-Coumaric acid content in leaves (C) and roots (D) of four grape genotypes after 0, 24 hours, 7 days and 14 days treated by $50 \mathrm{mM} \mathrm{NaCl}$. Different letters above the columns indicate significant difference $(P<0.05)$ between the treatments according to

Tukey's test.

\section{Sinapic acid}

Sinapic acid accumulated significantly $(P<0.05)$ in leaves and roots with time passing under salinity $(50 \mathrm{mM} \mathrm{NaCl})$. Leaves of Gharashani and roots of GhezelUzum showed higher content of sinapic acid compare to control (Figures 
5C and 5D). The difference among genotypes and also among treatments (time points) in leaves and roots was significant.
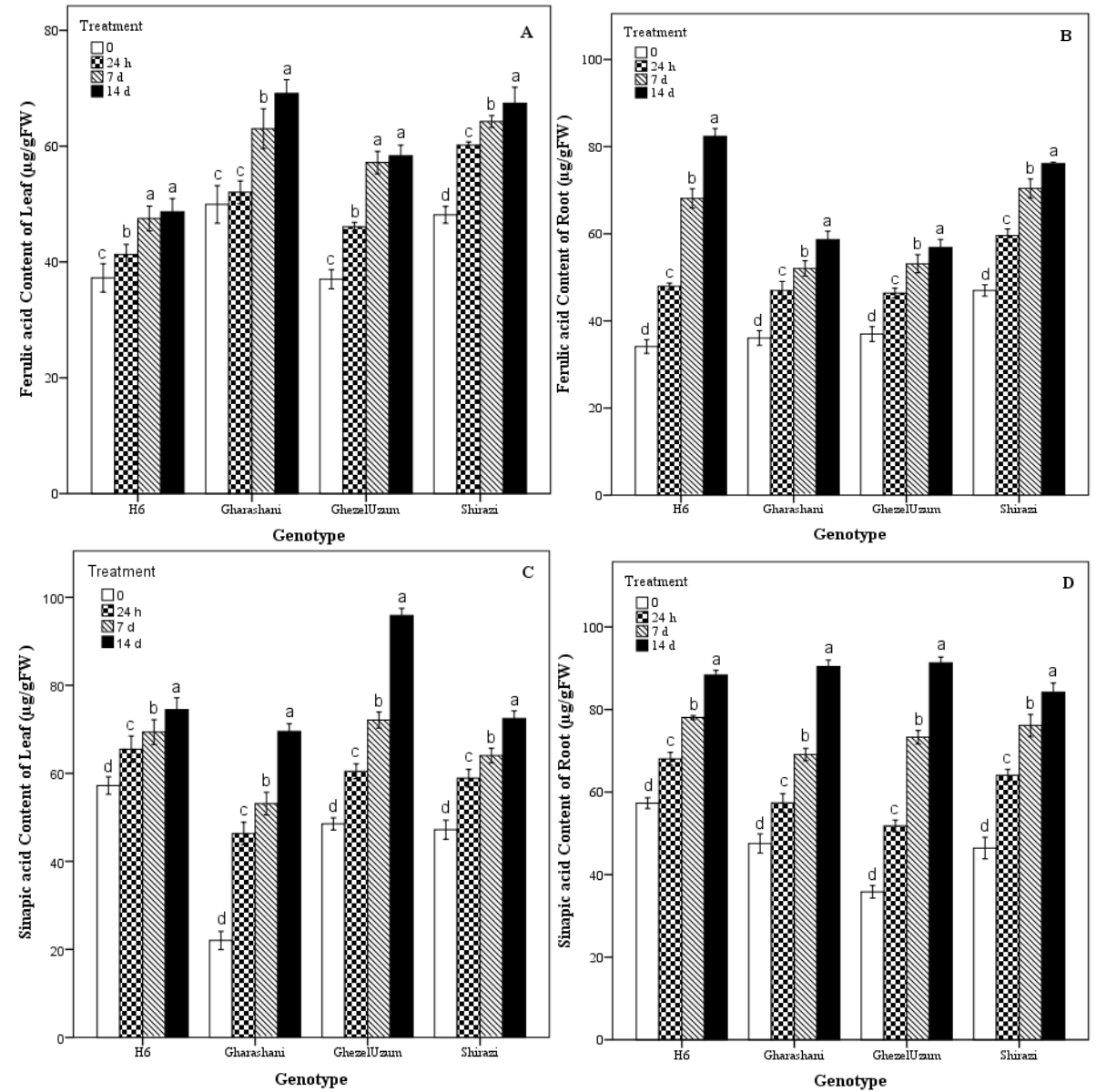

Figure 5. Ferulic acid content in leaves (A) and roots (B) and Sinapic acid content in leaves (C) and roots (D) of four grape genotypes after 0, 24 hours, 7 days and 14 days treated by $50 \mathrm{mM} \mathrm{NaCl}$. Different letters above the columns indicate significant difference $(P<0.05)$ between the treatments according to Tukey's test.

\section{Effects of salinity on other contents}

We assayed ascorbic acid and rutin contents, too.

Ascorbic acid increased in leaves and roots (Table 1). Leaves of Shirazi and roots of $\mathrm{H} 6$ showed higher accumulation of ascorbic acid compare to control. The difference among genotypes and also among treatments (time points) in leaves and roots was significant.

Rutin content first increased and then decreased in our genotypes, leaves of tolerant genotypes and roots of sensitive genotypes showed higher increase compare to control (Table 1). There was no significant difference between 
tolerant genotypes (Gharashani and H6) and also between sensitive genotypes (Shirazi and GhezelUzum) in leaves. The differences among all time points in leaves and roots was significant.

Table 1. Ascorbic acid and rutin content ( $\mu \mathrm{g} / \mathrm{g} \mathrm{FW}$ ) in leaves and roots of four grape genotypes after 0,24 hours, 7 days and 14 days treated by $50 \mathrm{mM} \mathrm{NaCl}$.

\begin{tabular}{|c|c|c|c|c|}
\hline $\begin{array}{c}\text { Genotype \& } \\
50 \mathrm{mM} \text { NaCl }\end{array}$ & $\begin{array}{c}\text { Ascorbic acid } \\
\text { Content of Leaf } \\
(\mu \mathrm{g} / \mathrm{g} \text { FW })\end{array}$ & $\begin{array}{c}\text { Ascorbic acid } \\
\text { Content of Root } \\
\text { ( } \mu \mathrm{g} / \mathrm{g} \text { FW) }\end{array}$ & $\begin{array}{c}\text { Rutin Content of } \\
\text { Leaf } \\
(\mu \mathrm{g} / \mathrm{g} \text { FW })\end{array}$ & $\begin{array}{c}\text { Rutin Content of } \\
\text { Root } \\
(\mu \mathrm{g} / \mathrm{g} \text { FW })\end{array}$ \\
\hline \multicolumn{5}{|l|}{ H6 } \\
\hline 0 & $4.81 \pm 0.15 \mathrm{~d}^{\mathrm{a}}$ & $8.73 \pm 0.35 \mathrm{~d}$ & $15.56 \pm 0.18 \mathrm{~b}$ & $15.61 \pm 0.26 \mathrm{~d}$ \\
\hline $24 \mathrm{~h}$ & $52.65 \pm 0.82 \mathrm{~b}$ & $19.50 \pm 0.33 \mathrm{c}$ & $19.35 \pm 0.16 \mathrm{a}$ & $16.71 \pm 0.15$ c \\
\hline $7 \mathrm{~d}$ & $60.30 \pm 0.45 \mathrm{a}$ & $35.30 \pm 0.66 \mathrm{~b}$ & $16.35 \pm 0.23 \mathrm{~b}$ & $19.14 \pm 0.06 \mathrm{a}$ \\
\hline $14 \mathrm{~d}$ & $31.22 \pm 0.28$ c & $54.46 \pm 0.53 \mathrm{a}$ & $16.41 \pm 0.24 \mathrm{~b}$ & $17.78 \pm 0.17 \mathrm{~b}$ \\
\hline \multicolumn{5}{|l|}{ Gharashani } \\
\hline 0 & $11.17 \pm 0.31 \mathrm{~d}$ & $25.28 \pm 0.37 \mathrm{~d}$ & $14.73 \pm 0.24 \mathrm{c}$ & $15.75 \pm 0.12$ c \\
\hline $24 \mathrm{~h}$ & $41.39 \pm 0.66 \mathrm{c}$ & $30.18 \pm 0.36 \mathrm{c}$ & $20.64 \pm 0.19$ a & $16.30 \pm 0.03 \mathrm{~b}$ \\
\hline $7 \mathrm{~d}$ & $100.54 \pm 0.36 \mathrm{a}$ & $48.33 \pm 0.48 \mathrm{~b}$ & $17.48 \pm 0.20 \mathrm{~b}$ & $18.99 \pm 0.12 \mathrm{a}$ \\
\hline $14 \mathrm{~d}$ & $87.73 \pm 0.55 \mathrm{~b}$ & $62.01 \pm 0.36 \mathrm{a}$ & $15.50 \pm 0.25$ c & $16.60 \pm 0.13 \mathrm{~b}$ \\
\hline \multicolumn{5}{|l|}{ GhezelUzum } \\
\hline 0 & $9.71 \pm 0.28 \mathrm{~d}$ & $4.72 \pm 0.06 \mathrm{~d}$ & $16.53 \pm 0.25$ c & $15.61 \pm 0.12 \mathrm{~d}$ \\
\hline $24 \mathrm{~h}$ & $27.59 \pm 0.52 \mathrm{c}$ & $7.69 \pm 0.18 \mathrm{c}$ & $19.55 \pm 0.32 \mathrm{a}$ & $19.38 \pm 0.26 \mathrm{~b}$ \\
\hline $7 \mathrm{~d}$ & $33.90 \pm 0.43 \mathrm{~b}$ & $14.97 \pm 0.38 \mathrm{~b}$ & $18.40 \pm 0.26 \mathrm{ab}$ & $21.06 \pm 0.15 \mathrm{a}$ \\
\hline $14 \mathrm{~d}$ & $61.29 \pm 0.49 \mathrm{a}$ & $19.59 \pm 0.32 \mathrm{a}$ & $17.47 \pm 0.26$ bc & $17.77 \pm 0.07$ c \\
\hline \multicolumn{5}{|l|}{ Shirazi } \\
\hline 0 & $5.68 \pm 0.20 \mathrm{~d}$ & $5.43 \pm 0.18 \mathrm{~d}$ & $16.21 \pm 0.18 \mathrm{~d}$ & $15.27 \pm 0.10 \mathrm{~d}$ \\
\hline $24 \mathrm{~h}$ & $13.75 \pm 0.15$ c & $8.28 \pm 0.20 \mathrm{c}$ & $19.59 \pm 0.09 \mathrm{a}$ & $18.17 \pm 0.12 \mathrm{a}$ \\
\hline $7 \mathrm{~d}$ & $51.62 \pm 0.24 \mathrm{~b}$ & $13.79 \pm 0.21 \mathrm{~b}$ & $18.74 \pm 0.25 \mathrm{~b}$ & $19.21 \pm 0.09 \mathrm{a}$ \\
\hline $14 \mathrm{~d}$ & $109.04 \pm 0.25 \mathrm{a}$ & $25.33 \pm 0.26 \mathrm{a}$ & $17.63 \pm 0.16 \mathrm{c}$ & $16.74 \pm 0.07 \mathrm{c}$ \\
\hline
\end{tabular}

${ }^{a}$ Different letters indicate significant differences $(P<0.05)$ according Tukey's multiple range tests.

\section{DISSCUSION}

Grapevine plants are moderately sensitive to salinity (Walker et al., 1981). Increase in phenol content could be an adaptive mechanism for tolerate stress. Several studies have reported that salt and drought stresses induce total phenol production (Hanen et al., 2008). Our results verified them, so that a regular ascendant process from control to long term salinity (14 days under $50 \mathrm{mM}$ $\mathrm{NaCl})$ was observed in all genotypes. However, this process was higher in tolerant genotypes (75\%) compare to sensitive ones (61\%). It seems that production of total phenolic compounds in tolerant genotypes was a part of their defense system against salinity.

Phenylalanine ammonia-lyase is a key enzyme that regulates the biosynthesis of phenolic compounds from phenylalanine. Phenolic acids are accumulated under stress as a result of increase in PAL activity and protect plants against abiotic stresses (Dixon and Paiva, 1995). In present study PAL activity increased under salinity. A significant positive correlation $(P<0.05, \mathrm{r} \geq 0.8)$ was observed between total phenolics and PAL activity in the leaves and roots of 
tolerant genotypes. Secondary metabolites as antioxidants, help the plants to tolerate oxidative stress. The accumulation of caffeic acid and p-coumaric acid help to reduce oxidative pressure, also caffeic acid and p-coumaric acid are good ROS scavengers (Rezazadeh et al., 2012). Szwajgier et al. (2005) reported that pcoumaric and ferulic acids showed the highest reducing power of free radicals.

In present study caffeic acid, p-coumaric and ferulic acid contents increased in all genotypes, but increase in caffeic acid content in leaves and roots of sensitive genotypes (GhezelUzum and Shirazi) was higher compare to tolerant ones. Whereas increase in p-coumaric in leaves and roots of tolerant genotypes was higher compare to sensitive ones. Also increase in ferulic acid content in leaves of sensitive genotypes and roots of tolerant ones was higher. It means that caffeic acid help to free radicals scavenging in sensitive genotypes more than tolerant and vice versa about p-coumaric acid.

The hydroxycinnamic acid derivatives are more strong antioxidants than hydroxybenzoic acid derivatives (Steenkamp et al., 2013). Increase in both hydroxycinnamic acid and hydroxybenzoic acid derivatives was observed in present study, it seems that accumulation of hydroxycinnamic acid derivatives was higher than hydroxybenzoic acid derivatives. Among hydroxybenzoic acid derivatives, Syringic acid increased higher. There was a significant positive correlation $(P<0.01, \mathrm{r}>0.8)$ between $\mathrm{p}$ - coumaric acid and ferulic acid contents (hydroxycinnamic acid derivatives) and also between p- hydroxyl benzoic acid and gallic acid (hydroxybenzoic acid derivatives) in roots of all genotypes. Most of phenolic acids in leaves was higher compare to roots, therefore grape leaves contain more phenolic acids than roots.

The synthesis of phenolic compounds is affected positively or negatively under different stresses. Plants synthesize different phenolic acids in response to abiotic stresses (Caldwell et al., 2007). Many authors reported the accumulation of phenols in plants under abiotic stresses (Dixon and Paiva, 1995; Weidner et al., 2009a). Differences in results can be related to type of stress, development stage, intensity and duration of stress and plant parts, such as roots or leaves (Weidner et al., 2009a). Variation among rootstocks in accumulation of biochemical compounds in response to salinity stresses observed. Increase in phenolic compounds was highest at the end of the stress (Parida et al., 2004).

Our results was consistent with them. In present study phenolic compounds accumulated in leaves and roots of both tolerant and sensitive grape genotypes under salinity, also our genotypes showed differences in accumulation of each compound. Accumulation of phenolic compounds was higher after 14 days salinity, but about some phenolic compounds some fluctuations was observed.

Jogaiah et al. (2014) reported the increase in phenols of tolerant grape rootstocks under salinity. That result is similar to Latha et al. (1989) study, where tolerant genotypes showed a higher total phenolics and decrease was observed in sensitive genotypes. Therefore increase in total phenols content of tolerant genotypes could be an adaptive mechanism for preventing damage during stress. 
Our results verified them about total phenolic compounds increase in tolerant genotypes. The sensitive genotypes showed increase in total phenolic compounds too, but that increase was higher in tolerant genotypes. Some phenolic derivatives increased higher in sensitive genotypes and others was higher in tolerant ones.

Phenolic acids were decreased in tissues during long-term stress (Kro'l et al., 2014). Similar results were reported by Weidner et al. (2011) in grape plants under osmotic stress, but caffeic acid increased. Phenolic synthesis in Shiraz variety during drought stress could also be limited (Ojeda et al., 2002).

Under chilling stress in leaves of $V$. vinifera, ferulic and caffeic acid contents increased, while p-coumaric acid decreased (Amarowicz et al., 2010). In addition, decrease in ferulic, caffeic and p-coumaric acids also have been reported in roots of grape plants at the same conditions. The highest phenolic in roots was p-coumaric acid and the lowest was caffeic (Weidner et al., 2009b).

Our results verified Kro'l et al. (2014), Ojeda et al. (2002) and Amarowicz et al. (2010) reports for some phenolic acids. Caffeic acid content in roots and pcoumaric acid content in leaves decreased at long term salinity, but the most of our phenolic compounds increased even under high salinity.

A significant positive correlation $(P<0.05, r>0.7)$ was observed between total phenolics contents and many of phenolic compounds in both tolerant and sensitive genotypes, $r$ value was higher in tolerant genotypes.

\section{CONCLUSION}

In conclusion PAL activity and total phenolics showed a significant positive correlations $(P<0.01)$ in tolerant genotypes. Phenolic compounds increased under salinity, some compounds accumulated higher in tolerant genotypes and some accumulated in sensitive genotypes. Therefore our tolerant and sensitive genotypes showed different defense mechanisms against salinity. But our tolerant genotypes were more successful and showed higher accumulation in phenolics content and PAL activity. Considering above mentioned results obtained in this study, because tolerant genotypes (H6 and Gharashani) possessed higher efficiency in its anti-oxidative system and can tolerate salinity better than sensitive ones, it seems that syringic and p-coumaric acids that was higher in tolerant genotypes, had an important role in salinity tolerance.

\section{REFERENCES}

Amarowicz R, Weidner S. 2009. Biological activity of grapevine phenolic compounds. In: Roubelakis-Angelakis KA. (Ed.) Grapevine molecular physiology and biotechnology, Springer, New York. pp. 389-405.

Amarowicz R, Weidner S, Wojtowicz I, Karmac' M, Kosin'ska A, Rybarczyk A. 2010. Influence of low-temperature stress on changes in the composition of grapevine leaf phenolic compounds and their antioxidant properties. Funct Plant Sci Biotech, 4: 90-96.

Bautista-Ortin AB, Fernandez-Fernandez JI, Lopez-Roca JM, Gomez-Plaza E. 2007. The effects of enological practices in anthocyanins, phenolic compounds and wine 
color and their dependence on grape characteristics. J Food Compos Anal, 20: 546-552.

Bonilla EP, Akoh CC, Sellappan S, Krewer G. 2003. Phenolic content and antioxidant capacity of Muscadine grapes. J Agric Food Chem, 51: 5497-5503.

Bub A, Watzl B, Blockhaus M, Briviba K, Liegibel U, Müller H, Pool-Zobel BL, Rechkemmer G. 2003. Fruit juice consumption modulates antioxidative status, immune status, and DNA damage. J Nutr Biochem, 14: 90-98.

Caldwell MM, Bornman JF, Ballare' CL, Flint SD, Kulandaivelu G. 2007. Terrestrial ecosystems, increased solar ultraviolet radiation, and interactions with other climate change factors. Photochem Photobiol Sci, 6: 252-266.

Castellano G, Tena J, Torrens F. 2012. Classification of phenolic compounds by chemical structural indicators and its relation to antioxidant properties of Posidonia oceanica L. Delile. MATCH Commun. Math Co, 67: 231-250.

Dixon RA, Paiva NL. 1995. Stress-induced phenylpropanoid metabolism. Plant Cell, 7: 1085-1097.

Fuleki T, Ricardo-Da-Silva MJ. 2003. Effects of cultivar and processing method on the contents of catechins and procyanidins in grape juice. J Agric Food Chem, 51: 640-646.

Guillen DA, Barroso CG, Perez JA. 1996. Selection of column and gradient for the separation of polyphenols in sherry wine by high performance liquid chromatography incorporating internal standards. J Chromatogr A, 724: 117-124.

Hakkinen SH, Karenlampi S, Heinonen IM, Mykkanen HM, Torronen AR. 1998. HPLC method for screening of flavonoids and phenolic acids in berries. J Sci Food Agric, 77: 543-551.

Hanen F, Ksouri R, Megdiche W, Trabelsi N, Boulaaba M, Abdelly C. 2008. Effect of salinity on growth, leaf phenolic content and antioxidant scavenging activity in Cynara cardunculus L. In: Abdelli C, Ozturk M, Ashraf M, Grignon YC. (Eds.) Biosaline agriculture and high salinity tolerance, Birkhauser Verlag, Switzerland. pp. 335-343.

Hounsome N, Hounsome B, Tomas D, Edwards-Jones G. 2008. Plant metabolites and nutritional quality of vegetables. J Food Sci, 73: 48-65.

Jogaiah S, Ramteke SD, Sharma J, Upadhyay AK. 2014. Moisture and salinity stress induced changes in biochemical constituents and water relations of different grape rootstock cultivars. Int J Agron, 2014: 1-8.

Jwa NS, Agrawal GK, Tomogami S, Yonekura M, Han O, Iwahashi H, Rakwal R. 2006. Role of defence/stress-related marker genes, proteins, and secondary metabolites in defining rice self defence mechanisms. Plant Physiol Biochem, 44: 261-273.

Kro'l A, Amarowicz R, Weidner S. 2014. Changes in the composition of phenolic compounds and antioxidant properties of grapevine roots and leaves (Vitis vinifera L.) under continuous of long-term drought stress. Acta Physiol Plant, 36: 14911499.

Latha VM, Satakopan VN, Jayasree H. 1989. Salinity induced changes in phenol and ascorbic acid content in groundnut (Arachis hypogaea) leaves. Curr Sci, 58: 151152.

Maas EV, Hoffman GJ. 1977. Salt crop tolerance - Current assessment. J Irrig Drain Eng, 6: 115-134.

Mohammadkhani N, Heidari R, Abbaspour N, Rahmani F. 2013. Comparative study of salinity effects on ionic balance and compatible solutes in nine Iranian table grape (Vitis vinifera L.) genotypes. J Int Sci Vigne Vin, 47: 99-114. 
Mohammadkhani N, Heidari R, Abbaspour N, Rahmani F. 2014. Evaluation of salinity effects on ionic balance and compatible solute contents in nine grape (Vitis L.) genotypes. J Plant Nutr, 37: 1817-1836.

Ojeda H, Andary C, Kraeva E, Carbonneau A, Deloire A. 2002. Influence of pre- and postvéraison water deficit on synthesis and concentration of skin phenolic compounds during berry growth of Vitis vinifera cv. Shiraz. Am J Enol Vitic, 53: 261-267.

Oueslati S, Karray-Bouraoui N, Attia H, Rabhi M, Ksouri R, Lachaal M. 2010. Physiological and antioxidant responses of Mentha pulegium (Pennyroyal) to salt stress. Acta Physiol Plant, 32: 289-296.

Parida AK, Das AB, Sanada Y, Mohanty P. 2004. Effects of salinity on biochemical components of the mangrove, Aegiceras corniculatum. Aquat Bot, 80: 77-87.

Posmyk MM, Kontek R, Janas KM. 2009. Antioxidant enzymes activity and phenolic compounds content in red cabbage seedlings exposed to copper stress. Ecotoxicol Environ Saf, 72: 596-602.

Rezazadeh A, Ghasemzadeh A, Brani M, Telmadarrehei T. 2012. Effect of salinity on phenolic composition and antioxidant activity of Artichoke (Cynara scolymus L.) leaves. Res J Med Plant, 6: 245-252.

Rice-Evans CA, Miller NJ, Paganaga G. 1997. Antioxidant properties of phenolic compounds. Trends Plant Sci, 2: 152-159.

Solecka D, Kacperska A. 2003. Phenylpropanoid deficiency affects the course of plant acclimation to cold. Physiol Plant, 119: 253-262.

Steenkamp V, Nkwane O, Tonder J, Dinsmore A, Gulumian M. 2013. Evaluation of the phenolic and flavonoid contents and radical scavenging activity of three southern African medicinal plants. Afr J Pharm Pharmacol, 7: 703-709.

Szwajgier D, Pielecki J, Targon'ski Z. 2005. Antioxidant activities of cinnamic and benzoic acid derivatives. Acta Sci Pol Technol Aliment, 4: 129-142.

Vekiari SA, Panagou E, Mallidis C. 2008. Extraction and determination of ellagic acid content in chestnut bark and fruit. Food Chem, 110: 1007-1011.

Walker RR, Torokfalvy E, Scott NS, Kriedemann PE. 1981. An analysis of photosynthetic response to salt treatment in Vitis vinifera. Aust J Plant Physiol, 8: 359-374.

Wang Y, Nii N. 2000. Changes in chlorophyll, ribulose bisphosphate carboxylaseoxygenase, glycine betaine content, photosynthesis and transpiration in Amaranthus tricolor leaves during salt stress. J Hortic Sci Biotechnol, 75: 623627.

Weidner S, Karolak M, Karamac' M, Kosin’ska A, Amarowicz R. 2009a. Phenolic compounds and properties of antioxidants in grapevine roots (Vitis vinifera) under drought stress followed by regeneration. Acta Soc Bot Pol, 78: 97-103.

Weidner S, Kordala E, Brosowska-Arendt W, Karamac' M, Kosin'ska A, Amarowicz R. 2009b. Phenolic compounds and properties of antioxidants in grapevine roots followed by recovery. Acta Soc Bot Pol, 78: 279-286.

Weidner S, Brosowska-Arendt W, Szczechura W, Karamac' M, Kosin'ska A, Amarowicz R. 2011. Effect of osmotic stress and post-stress recovery on the content of phenolics and properties of antioxidants in germinating seeds of grapevine Vitis californica. Acta Soc Bot Pol, 8: 11-19.

Xiong L, Schumaker KS, Zhu JK. 2002. Cell Signaling during Cold, Drought, and Salt Stress. Plant Cell, 14: 165-183. 